\title{
In Memoriam Prof. Todor Karchev, MD, PhD, DSc
}

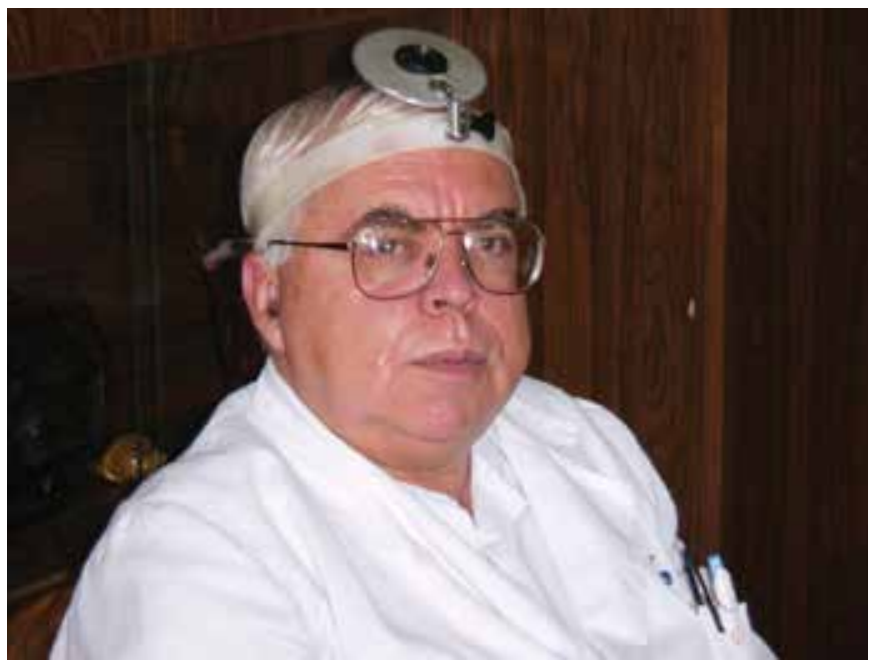

On 27 December 2013, at the age of 68, Prof. Todor Karchev passed away. We lost a globally recognised scientist, a respected teacher, a great man and a good friend.

Prof. Todor Karchev was born on 28 May 1945 in the town of Lyubimets. In 1969, he graduated with honours from Sofia Medical University and in 1970 he became Assistant Professor at the ENT Clinic of Sofia Medical University, where he worked until his retirement in 2012. In 1986, he was elected Associate Professor and in 1999 Professor. From 2000 to 2008, he was Head of the ENT Chair and ENT Clinic at the Medical University Sofia.

Prof. Karchev has more than 160 scientific publications, many of which are in international journals, and is the author or co-author of 6 books and one monograph. He contributed greatly to the problem of inflammatory diseases of the tonsils and adenoids. His work is reflected in his $\mathrm{PhD}$ thesis "Clinical and morphological studies of adenoid hyperplasia in children", defended in 1983, and his MSc thesis "Physiopathology of the tonsils", defended in 1997. He performed research in Poland (1979), Germany (1983), The Netherlands (1984) and Japan (1992-1993) and held many lectures in Poland, The Netherlands, Japan, Turkey and Greece, among which were: "Ultrastructure of the nasopharyngeal tonsil" (Warsaw, 1979), "Ultrastructural studies of scleroma respiratorium" (Utrecht, 1984), "M-cells in tonsillar epithelium" (Oita, 1987), "Septoplasty in children" (Tokyo, 1995), and "Mastoidoaditoatticotomy" (Ankara, 2002). He was the instructor of $6 \mathrm{PhD}$ students. Professor Karchev, Prof. G. Kabakchiev and Prof. E. Bogdanov were the first ENT surgeons in Bulgaria, and made instructional videos for ENT operations. As head of the Department of Otorhinolaryngology at the Medical University Sofia from 2000 to 2008, Professor Karchev established close relations with leading clinics in Germany, Austria, Greece, Turkey, South Korea and Great Britain, which paved the way for many young doctors to study their specialties abroad. In the department, cochlear implantation was started, which first introduced in Bulgaria by Prof. Ivan Tsenev in 1999. The educational process was improved by the implementation of modern multimedia devices. In 2008, together with Prof. Y. Spiridonova, Assoc. Prof. D. Popova, Assoc. Prof. M. Melnicharov and Dr. T. Shirov, a teaching team for English-speaking students was formed.

Prof. Karchev participated in the organising of scientific boards of many forums in Bulgaria, Italy, Poland, Netherlands, Hungary, the Czech Republic, Japan, Turkey, Greece, France, Belgium and the USA.

He was a member of the European Society of Pediatric Otorhinolaryngology (from 1971), European Rhinologic Society (from 1982), New York Academy of Science (from 1989), European Academy of Otology and Neuro-Otology (from 1994), and a Corresponding Member of the German Academy of Otorhinolaryngology, Head and Neck Surgery (from 2007).

He was President of the Sofia ENT Society (1993-2007), Vice-President of Bulgarian ENT Society (2000-2010), Secretary of the Scientific Council of Ophthalmology and Otolaryngology at HAC and President of Balkan Society of Otorhinolaryngology (2001-2005), and a member of the EUFOS Executive Board. From 2001, he was chief editor of the journal Otorhinolaryngology.

Prof. Karchev was a member of the Bulgarian Academy of Sciences and Arts (BASA) from its establishment in 2004. BASA is an independent non-governmental organisation and civil Institute, a successor of the ideas and work of the Bulgarian Academy of Sciences and Arts, which closed in 1947.

He was Chairman of the Board of the Foundation "Stoyan Belinov" and organiser of the annual Belinov symposium with international participation. In connection with this, a prize in the name of Prof. Stoyan Belinov was established, which is awarded to prominent Bulgarian otorhinolaryngologists.

Thanks to his efforts and international contacts, the tradition for Balkan ENT congresses was revived and the IV Balkan Congress was held in Sunny Beach in 2004. 
In 2003, Professor Karchev was decorated as a "Physician of Bulgaria".

Professor Karchev was a man of great moral and professional value. He truly liked people, and that is why people also liked him very much. His presence cannot be replaced. He was and will remain one of the brightest representatives of Bulgarian otorhinolaryngology.

Bow to his memory!
Stefan Stoyanov, Head of ENT Clinic

Medical Institute, Ministry of Interior, Sofia, Bulgaria

Anna Valkova, ENT Chair

Queen Joanna University Hospital, Sofia Medical University, Sofia, Bulgaria

DOI: 10.5152/balkanmedj.2014.14001 